\title{
The Relationship between Self-efficacy and Stress among Iranian EFL Teachers
}

\author{
Shahin Vaezi \\ Department of Foreign Languages, Iran University of Science and Technology, Iran \\ Email: sh_vaezi@iust.ac.ir \\ Nasser Fallah \\ Department of Foreign Languages, Iran University of Science and Technology, Iran \\ Email: nfallah@lang.iust.ac.ir
}

\begin{abstract}
This study investigated the relationship between self- efficacy and stress among 108 EFL teachers in Iran. The participants were administered self-efficacy and stress questionnaires. Pearson Product-Moment Correlation and Multiple Regression analyses were used. The results indicated significant negative correlation between self efficacy and stress. Also it was found that both dimensions of self-efficacy, namely, classroom and organizational efficacies, either collectively or separately, could predict stress among EFL teachers. Implications of the study are discussed.
\end{abstract}

Index Terms—stress, self-efficacy, EFL teachers, organizational efficacy, classroom efficacy

\section{INTRODUCTION}

Teacher stress has increasingly been recognized as a widespread problem in different educational settings (e.g., Boyle, Borg, Falzon, \& Baglioni, 1995; Dick \& Wagner, 2001; Kyriacou, 2001). Compared to the general population, teachers are at risk for higher levels of psychological distress and lower levels of job satisfaction (Travers \& Cooper, 1996; Schonfield, 1990). Borg (1990) also reported that up to one third of teachers perceive their occupation as highly stressful.

Although the reasons may differ, all teachers may experience stress in their job (Jennett, Harris \& Mesibov, 2003). However, even encountering similar work stress, some teachers may be less vulnerable to stress than others. Therefore, it seems natural that one should raise the question as to why some teachers could be less vulnerable to stress than others in the face of similar work stress. In this connection, an examination of personal resources in coping and managing one's affective experience seems advisable. One personal coping resource that is the concern of the present study is self-efficacy. Bandura (1995) stated that people with high efficacy beliefs persisted with the task in the face of difficulty and achieved higher results with lower levels of stress. Besides, self-efficacy beliefs can augment human accomplishment and well-being in numerous ways (Pajares, 2002). This is particularly true when it comes to professions such as teaching, with its emotionally challenging nature, high levels of affective involvement, complexity and constant interaction. However, a review of the related literature reveals that self efficacy has not received attention in the study of teacher stress in the realm of EFL teaching. Definitely, the scarcity of research in this area provides a convincing rationale to undertake further investigation into examining the relationship between EFL teachers' selfefficacy and their stress.

\section{LITERATURE REVIEW}

\section{A. Teacher Stress}

Stress is usually considered to be the effect or the response to a stimulus (Jenkins \& Calhoun 1991). Among the individual affective factors, stress has been cited as one of the most important variables and this concept has gradually become common in our discourse about life and health (Jepson \& Forrest 2006). Some researchers defined stress in terms of the level of pressure and demands made on an individual. Other researchers have defined the term by means of the degree of mismatch between the demands made upon an individual and the individual's ability to cope with these demands (Kyriacou, 2001).

Kyriacou and Sutcliffe (1979) described teacher stress as a response syndrome of negative affect (such as anger and depression), usually accompanied by physiological changes (such as increased heart rate) resulting from aspects of the teacher's job and mediated by the perception that the demands made upon the teacher constitute a threat to his or her self-esteem or well being. In identifying sources of teacher stress, different investigators in different settings have come up with a diversity of stressors that include students' misbehaviors and discipline problems, students' poor motivation for work, heavy workload and time pressure, role conflict and role ambiguity, conflicting staff relationships in school 
management and administration, and pressure and criticisms from parents and the wider community (see Dunham, 1992; Travers \& Cooper, 1996).

Like teachers in other fields, nowadays, EFL teachers have heavier responsibilities than before. Innovations in the field of education and language teaching have created a rather new role for teachers. Teachers are no longer considered as the mere transferors of knowledge, but as individuals who are required to communicate and engage with students more than before and to care for their inner worlds (Arnold 1999).

EFL teachers should empathize with learners, try to keep them motivated and encourage them to participate in classroom activities. However, besides these roles, they are also supposed to engage in many other tasks such as paperwork, evaluating students, preparing for the class and keeping themselves up-to-date with their teaching area. At the same time, they might have positive or negative encounters with parents, colleagues, administrative authorities and students, all of which can affect them psychologically (Mousavi, 2007). The combination of all factors such as these may make the individual teacher feel more accountable than before, yet more confused, and arguably less supported (Claxton 1989).

Several experimental studies have been conducted on teacher stress. Travers and Cooper (1997), for example, surveyed 800 teachers in England and France about stress and found substantially different responses. $22 \%$ of sick leave in England, as opposed to $1 \%$ in France was attributed to stress. 55\% of the English teachers as opposed to $20 \%$ of the French sample reported recently considering leaving teaching. Interestingly, there was substantial agreement between the English and French teachers as to the sources of pressure, both groups citing classroom discipline, low social status and lack of parental support. However, English teachers reported more problems with long hours, overwork and political interference.

Pithers and Soden (1998) has highlighted role overload as a significant stressor in teachers. They assessed levels of strain, organizational roles and stress in 322 Australian and Scottish vocational lecturers. Strain was found to be average in both national groups, but there were high levels of stress, with role overload emerging as the major cause.

Lewis (1999) examined teachers' estimations of stress arising from being unable to discipline pupils in the way they would prefer. Overall, maintaining discipline emerged as a stressor, with those worst affected being teachers who placed particular emphasis on pupil empowerment. (Morton et al, 1997) conducted a study of 1000 student teachers. The results revealed that classroom management was their second greatest sources of anxiety, the greatest being evaluation apprehension. Of all the stressors reported, classroom management anxiety was the only one that did not decline following teaching practice.

Finally a study of a group of EFL teachers showed that the main sources of stress were lack of sufficient time, unwanted classroom observations and poor relations with colleagues (Bress 2006).

\section{B. Self-efficacy}

\section{Sources of Self-efficacy Beliefs}

Perceived self efficacy, i.e., "beliefs in one's capabilities to organize and execute the courses of action required producing given attainments" (Bandura, 1997, p. 3), can be developed by four main sources of influence. Bandura (1997) postulated these sources of efficacy expectations as: mastery experience, also called enactive self-mastery, vicarious experience, also called role-modeling, social or verbal persuasion, and arousal or physiological and emotional states.

The first source, enactive mastery experiences, is the most influential and is comprised of all the successes one has experienced in specific environments. An individual's frequent successes, especially those accompanied with overcoming adversity, build robust self efficacy beliefs that fine tune abilities to better control events (Bandura 1997). Secondly, vicarious experiences are gained through observation of events that have been modeled by others. They enable the observer to appraise his own capabilities in relation to the attainments of others (Bandura, 1997). Of course, the effects on self efficacy vary with the skill of the modeler, but watching someone with capabilities similar to the observer raises the self-efficacy beliefs of the observer. Observing modeled behavior convinces the observer that the achievement outcome will be the same. On the contrary, observing similar people who fail lowers the individual's confidence and subsequently undermines their efforts (Bandura, 1997). The third source of influence is social or verbal persuasion received from others. Successful persuaders foster people's beliefs in their capabilities, while at the same time, ensure that the visualized success is achievable. Negative persuasion, on the other hand, may tend to defeat and lower self-beliefs. The most contributing effect of social persuasion pivots around initiating the task, attempting new strategies, and trying hard to succeed (Pajares, 2002). Psychological and affective states, such as stress, anxiety, and excitement also provide information about efficacy perception and boost the feeling of proficiency. Hence, trying to reduce an individual's stress and anxiety and modify negative debilitative states to positive facilitative states plays an influential role in amending perceived self-efficacy beliefs (Bandura, 1997).

\section{Teacher's Self-efficacy}

Teacher efficacy is defined as "the teacher's belief in his or her capability to organize and execute courses of action required to successfully accomplish a specific teaching task in a particular context" (Tschannen-Moran et al., 1998, p. 22).

Friedman and Kass (2002) developed a new conceptualization of teacher self-efficacy, named Classroom and School Context (CSC). It is multi-faceted and detailed, and relates to a wide range of teacher functioning. According to the 
CSC conceptualization, the teacher's functioning within the school is comprised of two basic domains: (a) the classroom, where the teacher works with students, and (b) the school, where the teacher functions as a member of an organization. The importance of the Friedman and Kass (2002) model for the purpose of this study is that, besides classroom considerations, such as, teacher's functioning as an educator and flexibility within the classroom and nurturing social relations among the students it contains an organizational efficacy component, which was not found in other definitions of teacher efficacy as proposed by other scholars. The organizational domain of the teacher functioning at school has a markable effect on the teacher as an employee (Cherniss, 1993).

As an organizational person the teacher may possibly seek influence and active involvement in performing organization-related tasks (involvement in decision making, confidence in functioning in the organizational domain, and ascending the school hierarchy), as well as establishing positive relations with colleagues and members of the administration, assertiveness and social integration, and affording a sense of belonging and security.

With reference to the educational setting, self-efficacy has been found to positively correlate with academic achievement. Research findings have established that students' self-efficacy beliefs are correlated with other motivation constructs and with students' academic performance and achievement (see, Ashton and Webb, 1986; Lent and Hackett, 1987). Several studies have also established that teachers with a strong sense of efficacy tend to exhibit greater levels of planning, organization, and enthusiasm. They persist when things do not go smoothly and are more resilient in the face of setbacks. They tend to be less critical with students who make errors and work longer with a student who is struggling (Ashton and Webb, 1986; Coladarchi, 1992, Gibson and Dembo, 1984; Tschanhen-Moran and Woolfolk 2001). A strong sense of teacher's self-efficacy promotes a firm commitment to the profession and collaborative relationships with colleagues and parents (Coladarci, 1992), contributing fruitfully to the promotion of a rich and stimulating learning environment. Ross (1994) reviewed 88 teacher efficacy studies in pre-college settings and identified potential links between teachers' sense of efficacy and their behaviors. He reported that teachers with higher levels of efficacy are more likely to learn and use new approaches and strategies for teaching, provide special assistance to low achieving students, and persist in the face of student failure.

Grau, Salanova and Peirò (2001) found that self-efficacy could moderate work- related stress. Professional selfefficacy was found to be negatively associated with burnout. Chwalisz, Altmaier and Russell (1992) examined the extent to which teachers' causal attributions of their sense of job stress and perceived efficacy to manage stressors affected their style of coping, and the different types of burnout reactions. They found that perceived occupational inefficacy was an important mediator of burnout.

\section{PURPOSE OF THE STUDY}

As noted earlier, much research has been conducted on self-efficacy (e.g., Ross, 1994; Tschannen-Moran et al., 1998) and on stress (e.g., Boyle, Borg, Falzon, \& Baglioni, 1995; Dick \& Wagner, 2001), but little has been carried out or reported on the relationship between these two; however, those studies are mainly limited to the L1 environment. Since these two factors, teacher self efficacy and stress, are of current concern in all levels of education (Tschannen-Moran et al., 1998) and since increasing self efficacy and lowering stress contribute to teaching effectiveness (Pajares, 1992), it seems that some research should be carried out in EFL context to examine if and how these two factors are related. In summary, the present study seeks to investigate the relationship between EFL teachers' self-efficacy beliefs and their stress in private institute context. To this end, the present study seeks; first, to investigate the relationship between EFL teachers' self-efficacy and stress, second, to investigate which dimension(s) of teachers self-efficacy can contribute to the prediction of stress among EFL teachers.

\section{METHODOLOGY}

\section{A. Participants and Procedures}

The participants in this study consisted of 108 EFL teachers ( 52 females and 56 males) aged between 20 and 47 years old $(\mathrm{M}=28.43, \mathrm{SD}=5.12)$ with a range of between 1 and 19 years of teaching experience $(\mathrm{M}=6.52, \mathrm{SD}=3.93)$. Sixty teachers held BA degree, forty four MA and four had $\mathrm{PhD}$ degree in one of these fields: English Language Teaching, English Translation and English Literature. The participants were chosen from 6 language institutes in Tehran.

The study was carried out at the beginning of the summer semester, 2010. The participants took the questionnaires home, filled them in and submitted it to the researchers within a week. To receive reliable data, the researchers explained the purpose of the study to the participants, and assured them that their information would be confidential.

\section{B. Instruments}

Two questionnaires measuring EFL teachers self-efficacy and stress along with a subject fact form enquiring about teachers' demographics, namely, age, gender and teaching experience served as the research tools in the present study.

\section{Teacher Stress Inventory (TSI)}

Teacher stress was measured using the Teacher Stress Inventory (TSI). The TSI was developed by Fimian (1984) to measure teachers' perception of stress as it relates to their occupation. The TSI includes 49 items on a 5 point Likert scale, and it covers 10 factors which are broken down into stress factors and stress manifestations. The five stress source 
factors are Time Management, Work-Related Stressors, Professional Distress, Discipline and Motivation, and Professional Investment. The five stress manifestations factors are Emotional Manifestations, Fatigue Manifestations, Cardiovascular Manifestations, Gastronomic Manifestations, and Behavioral Manifestations. The reliability estimate of the scale for the present study was $\alpha=0.91$.

\section{Self-efficacy Scale}

Reviewing the existing measures on teacher's self-efficacy (such as, the Webb Efficacy Scale developed by Ashton, Olejnik, Crocker and McAuliffe (1982), including seven items; the teacher efficacy scale by Gibson and Dembo (1984), including 30 items on a 6 point Likert scale; Bandura's teacher efficacy scale, 1997, comprising 30 items on a 9 point scale; Teacher Sense of Efficacy Scale by Tschannen-Moran and Woolfolk Hoy, 2001), the researchers decided to utilize Friedman and Kass's (2002) Teacher Self Efficacy Scale. The rationale for utilizing this scale is twofold: First, it contains several aspects of efficacy beliefs, thus providing a higher resolution of this concept. Secondly, it contains an organizational aspect of teacher functioning, which was found to be an important factor in explaining stress (Cherniss, 1993). The Teachers Self efficacy Scale is based on Classroom and School Context (CSC) model of teacher selfefficacy, as introduced by Friedman and Kass (2002). The scale includes 33 items. As mentioned before, it measures teacher self efficacy in two domains of functioning, classroom context (sense of professional efficacy pertaining to teaching, educating and motivating students, as well as controlling inter-relations with students) and school context (involvement in school activities, participation in decision-making and influencing school organizational politics). The classroom context subscale consists of 19 items and the school context subscale includes 14 items. The response options for the items ranged from 1 (never) through 6 (always). In this study the reliability estimates for subscales were $\alpha=0.89$ for classroom context (classroom efficacy dimension) and $\alpha=0.87$ for school context (organizational efficacy dimension).

\section{RESULTS}

\section{A. The Relationship between Teacher Self-efficacy and Stress}

In order to test the relationships between teachers' self efficacy and stress, a Pearson Product-Moment Correlation analysis was run. The result indicated that there was significant negative correlation between self-efficacy and stress ( $\mathrm{r}$ $=-0.47, \mathrm{p} \square 0.01)$ (see Table 1). To clarify further, Scatter Plots also showed that the higher teachers' self-efficacy, the lower their stress level (see Figure 1).

TABLE 1:

THE RESULTS OF CORRELATION BETWEEN TEACHERS STRESS, AGE AND YEARS OF TEACHING EXPERIENCE

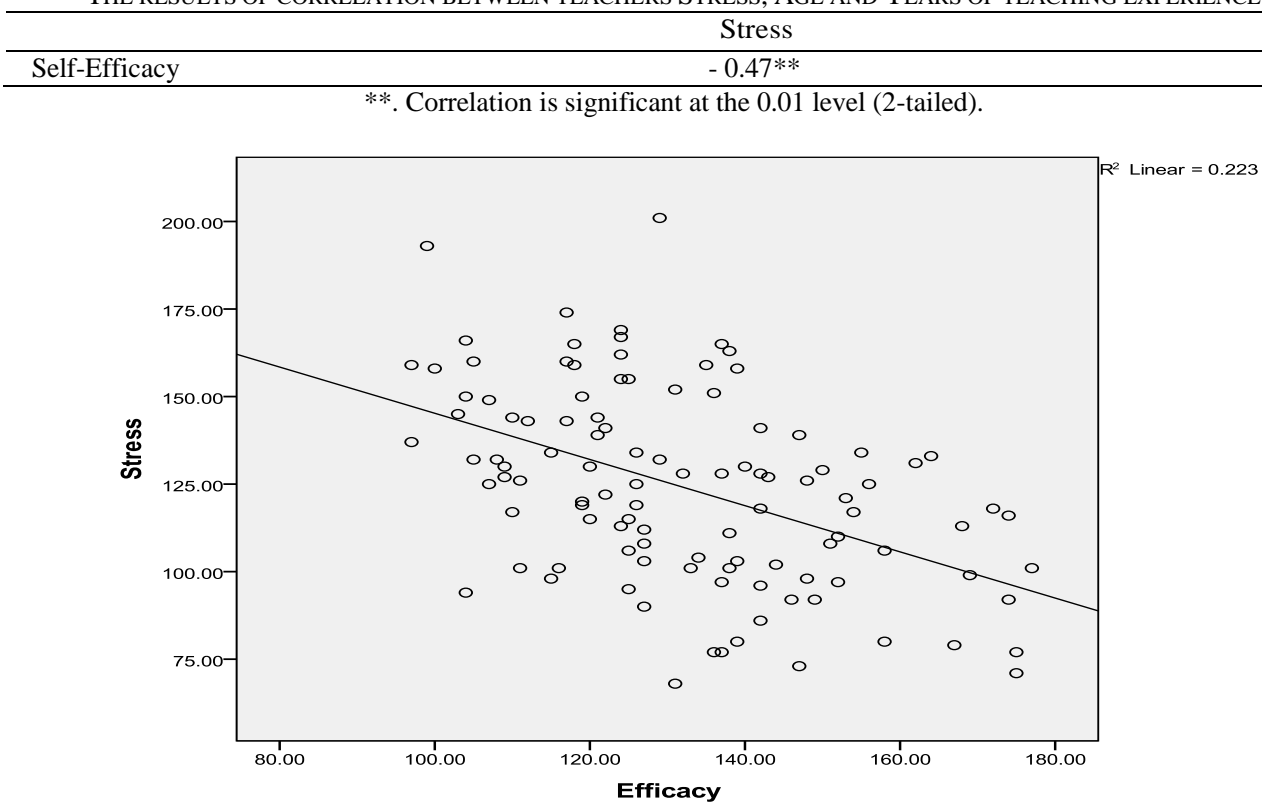

Figure 1: The Relationship between Self-Efficacy and Stress

\section{B. Contribution of the Two Dimensions of Teacher Self-efficacy to the Prediction of Stress}

To determine which dimension(s) of Self efficacy can predict stress in EFL teachers, a multiple regression analysis was run. In this analysis, $\mathrm{R}^{2}=.22, \mathrm{~F}(2,107)=15.11$ and $\mathrm{p} \square .01$, indicating that $22 \%$ of the variance in stress is explained by the combination of the independent variables, namely, Classroom efficacy and Organizational efficacy (see table 2). 
According to the results displayed in table 2 above, each of the independent variables made significant individual contributions to the prediction of Stress as follows: Classroom efficacy $(\beta=.32, t=3.59, \mathrm{p} \square .01)$ and Organizational efficacy $(\beta=.27, \mathrm{t}=3.04, \mathrm{p} \square .01)$.In this analysis the correlation between the predictive variables was 0.26 ( $\mathrm{p}<01$ ).

TABLE 2:

\begin{tabular}{|c|c|c|c|c|c|c|c|}
\hline Predictors & $\mathrm{R}$ & $\overline{\mathrm{R}^{2}}$ & $\mathrm{~F}(2,107)$ & $\mathrm{B}$ & SEM & $\operatorname{Beta}(\beta)$ & $\mathrm{t}$ \\
\hline & .47 & .22 & $15.11^{* * *}$ & & & & \\
\hline $\begin{array}{l}\text { Classroom } \\
\text { Efficacy }\end{array}$ & & & & -.64 & .18 & -.32 & $-3.59 * *$ \\
\hline $\begin{array}{l}\text { Organizational } \\
\text { Efficacy }\end{array}$ & & & & -.67 & .22 & -.27 & $-3.04 * *$ \\
\hline
\end{tabular}

\section{DISCUSSION}

Since changing the educational system is no easy task it is necessary to deepen our understanding of individuals' coping resources that may mediate the appearance of stress. To this end, the present study sought to explore the relationship between self-efficacy and stress among EFL teachers in private institutes.

The results indicated that there was a significant negative relationship between teachers self efficacy and stress. The size of this correlation indicates that the higher the teachers' self- efficacy, the less likely they were to experience stress in their profession. This is in accordance with previous theoretical and empirical studies on the role of self-efficacy in stress, though these are limited where teachers are concerned, and quite sparse in the foreign language context altogether. Efficacy beliefs influence the amount of stress and anxiety individuals experience as they engage in an activity (Bandura, 1997). As pointed out by Bandura (2000) people with high confidence in their capabilities handle stress related factors effectively and approach difficult tasks as challenges to be mastered rather than as threats to be avoided. The results of a study conducted in Spain revealed that teachers with a higher self efficacy were less stressed and more motivated and satisfied in their profession (Betoret, 2006). In addition, Cadiz (1989) suggested that teachers benefit from having strong self-efficacy to cope better with stress.

The results also revealed that both dimensions of self-efficacy, classroom and organizational efficacies, either collectively or separately were potent predictors of teacher stress. However, it was shown that classroom efficacy was a better predictor of stress among the participants.

By the nature of the construct of organizational efficacy, it is expected that teachers' positive perception of themselves as employees of an organization in which they are constantly interacting with others (e.g., colleagues, principal, and supervisors) will have a buffering effect on work related stress. The findings of the present study corroborate Cherniss's (1993) assertion that the organizational domain of the teacher functioning at school has a remarkable effect on the teacher as an employee. A positive school climate, one that is supportive, helpful, cooperative, and respectful of teachers, was negatively related to teacher stress and burnout (Sava, 2002). On the other hand, preventing teachers from participating in decisions on teacher-related issues will result in declining employees' morale, dissatisfaction and professional esteem (Smylie, 1999). Eventually, these cumulative effects will manifest themselves in professional stress and burnout (Byrne, 1994).

However, one plausible explanation for the higher strength of classroom efficacy in predicting stress is that teachers with a low sense of classroom efficacy, more specifically instruction efficacy, tend to become mired in classroom problems, are stressed and angered by student misbehavior, pessimistic about student potential to improve, and focus more on subject matter than student development. Teachers with high sense of organizational efficacy believe that unmotivated students can be taught, given the extra effort and appropriate techniques; that family support can be enlisted; and that negative community influences can be overcome through effective teaching (Gibson and Dembo, 1984). This can either help buffer the deleterious effects of job stress, or directly improve teacher's well-being.

\section{CONCLUSION}

In essence, the yielded results of the current study lead to the conclusion that enhancing teachers' self-efficacy tends to have a positive influence on diminishing their stress. This in turn may lead to amelioration of teachers' well-being, prosocial behavior, motivation and teaching effectiveness and accordingly students' achievement. Thus, the findings underline the importance of establishing some courses for EFL teachers to focus particularly on Bandura's (1997) four strategies for increasing efficacy providing opportunities for mastery experiences, physiological and emotional arousal, vicarious experience, and social persuasion. Also group-centered in-service training or peer coaching directed at strengthening teachers' self-efficacy beliefs may prove to be an effective means of stress reduction (Stein \& Wang, 1988).

Based on the finding of the present study, EFL teachers should develop skills in monitoring their stress levels. Research by Cockburn (1996) concluded that the first step for teachers in reducing stress is to develop their awareness of stress levels. Only when a teacher understands and monitors his or her stress levels can steps be taken to control the 
level of stress. Also teachers and school administrators should collaborate to discuss the sources and consequences of teacher stress as well as ways to alleviate it. Some sources of teacher stress have been documented in the literature, but each school context is likely to have unique sources of stress, specific to that context that need to be addressed. Besides, it is recommended that school authorities and teachers do more to enhance and strengthen the organizational aspect of teaching, that is, the capacity to work as an employee receiving services, assistance and support from others (e.g., colleagues, supervisors, and chancellor). Social support within the organization and organizational support in general can reduce stress (Friedman, 2000).

The findings of the current study, however, must be treated with caution. To the researchers' best knowledge, this is the first attempt to explore the relationship between EFL teachers' self-efficacy and their stress. Thus, this study should be replicated with more numbers of participants to find out whether similar results can be obtained elsewhere. Also to obtain a more precise estimate of teacher self efficacy and stress, future research should combine self reporting measures with other measures based on objective performance.

\section{REFERENCES}

[1] Arnold, J. (Ed). (1999). Affect in Language Learning. Cambridge: Cambridge University Press.

[2] Ashton, P. T., Olejnik, S., Crocker, L. \&, McAuliffe, M. (1982). Measurement problems in the study of teachers' sense of efficacy. In: Paper Presented at the Annual Meeting of the American Educational Research Association, New York.

[3] Ashton, P.T., \& Webb, R.B. (1986). Making a difference: Teachers' sense of efficacy and student achievement. New York: Longman.

[4] Bandura, A. (1995). Self-efficacy in changing societies. Cambridge: Cambridge University Press.

[5] Bandura, A. (1997). Self-efficacy: The exercise of control. New York: W. H. Freeman.

[6] Bandura, A. (2000). Cultivate self-efficacy for personal and organizational effectiveness. In E.A. Locke (Ed.), Handbook of principles of organization behavior (pp. 120-136). Oxford U.K. Balckwell.

[7] Betoret, F. D. (2006). Stressors, self-efficacy, coping resources, and burnout among secondary school teachers in Spain. Educational Psychology, 26 (4), 519-539.

[8] Borg, M. (1990). Occupational stress in British educational settings: A review. Educational Psychology, 10, 103-126.

[9] Boyle, G. I, Borg, M. G., Falzon, I. M., \& Balioni, A. I. (1995). A structural model of the dimensions of teacher stress. British Journal of Educational Psychology, 65, 49-67.

[10] Bress, P. (2006). Beating stress: Creating happiness and well-being in TEFL. Modern English Teacher 15 (3), 5-15.

[11] Byrne, B. M. (1994). Burnout: Testing for the validity, replication, and invariance of causal structure across elementary, intermediate, and secondary teachers. American Educational Research Journal, 31(3), 645-673.

[12] Cadiz, S. (1989). The continuum of teacher training: A developmental approach to teacher preparation. Educational Research Journal, 31 (3), 645-673.

[13] Cherniss, C. (1993). Role of professional self-efficacy in the etiology and amelioration of burnout. In W.B. Shaufeli, C. Maslach, \& T. Marek (Eds.), Professional burnout: Recent developments in theory and research. Washington, D.C.: Taylor \& Francis.

[14] Chwalisz, K., Altmaier, E. M., \& Russell, D. W. (1992). Causal attributions, self-efficacy cognitions, and coping with stress. Journal of Social and Clinical Psychology, 11, 377-400.

[15] Claxton, G. (1989). Being a teacher: A positive approach to change and stress. London: Cassell Educational Limited.

[16] Cockburn, A. D. (1996). Primary teachers' knowledge and acquisition of stress relieving strategies. British Journal of Educational Psychology, 66, 399-410.

[17] Coladarci, T. (1992). Teachers' sense of efficacy and commitment to teaching. Journal of Experimental Education, 60 (4), $323-$ 337.

[18] Dick, R. V., \& Wagner, U. (2001). Stress and strain in teaching: A structural equation approach. British Journal of Educational Psychology, 71, 243-259.

[19] Dunham, J. (1992). Stress in teaching (2nd ed.). London: Routledge.

[20] Fimian, M. J. (1984). The development of an instrument to measure occupational stress in teachers: The Teacher Stress Inventory. Journal of Occupational Psychology, 57, 277-293.

[21] Friedman, I. A. (2000). Burnout in teachers: Shattered dreams of impeccable professional performance. Journal of Clinical Psychology, 56, 595-606.

[22] Friedman, I. A., \& Kass, E. (2002). Teacher self-efficacy: a classroom-organization conceptualization. Teaching and Teacher Education, 18, 675-686.

[23] Gibson, S., \& Dembo, M.H. (1984). Teacher efficacy: A construct validation. Journal of Educational Psychology, 76, 569-582.

[24] Grau, R., Salanova, M., \& Peirò, J.M. (2001). Moderator effects of self-efficacy on occupational stress. Psychology in Spain, 5 (1), 63-74.

[25] Jenkins, S., \& J. Calhoun. (1991). Teacher stress: Issues and intervention. Psychology In The Schools, 28,60 - 70.

[26] Jennett, H. K., Harris, S. L., \& Mesibov, G. B. (2003). Commitment to philosophy, teacher efficacy, and burnout among teachers of children with autism. Journal of Autism and Developmental Disorders, 33, 583-593.

[27] Jepson, E., \& S. Forrest. (2006). Individual contributory factors in teacher stress: The role of achievement striving and occupational commitment. British Journal of Educational Psychology, 76, 183-197.

[28] Kyriacou, C., \& Sutcliffe, J. (1979). A note on teacher stress and locus of control. Journal of occupational Psychology. 52, $227-228$.

[29] Kyriacou, C. (2001). Teacher stress: Directions for future research. Educational Review 53 (1), 27-35.

[30] Lent, R. W., \& Hackett, G. (1987). Career self-efficacy: Empirical status and future directions. Journal of Vocational Behavior, $45,421-431$. 
[31] Lewis R (1999). Teachers coping with the stress of classroom discipline. Social Psychology of Education 3, 155-171.

[32] Morton L. L., Vesco R., Williams N. H., \& Awender M. A. (1997). Student teacher anxieties related to class management, pedagogy, evaluation and staff relations. British Journal of Educational Psychology, 67, 69-89.

[33] Mousavi, E. S. (2007). Exploring teacher stress in non-native and native teachers of EFL. ELTED, 10, 33-41.

[34] Pajares, M. F. (1992). Teachers' beliefs and educational research: clearing up a messy construct. Review of Educational Research, 62 (3), 307-332.

[35] Pajares (2002). Self-efficacy beliefs in academic contexts: An outline. Retrieved Jun 8, 2010, from http://des.emory.edu/mfp/efftalk.html.

[36] Pithers, R. T., \& Soden R. (1998). Scottish and Australian teacher stress and strain: A comparative study. British Journal of Educational Psychology, 68, 269-279.

[37] Ross, J. A. (1994). Beliefs that make a difference. The origins and impacts of teacher efficacy. Paper presented at the annual meeting of the Canadian Association for Curriculum Studies.

[38] Sava, F. A. (2002). Causes and effects of teacher conflict-inducing attitudes towards pupils: A path analysis model. Teaching and Teacher Education, 18, 1007-1021.

[39] Schonfeld. I. (1990). Psychological distress in a sample of teachers. The Journal of Psychology,123, 321-338.

[40] Smylie, M.A. (1999). Teacher stress in a time of reform. In R. Vandenberghe \& Huberman, A.M. (Eds.), Understanding and preventing teacher burnout (pp. 59-84). Cambridge: Cambridge University Press.

[41] Stein, M. K., \&Wang, M. C. (1988). Teacher development and school improvement: The process of teacher change. Teaching and Teacher Education, 4 (2), 171-187.

[42] Travers, C. J., \& Cooper, C. L. (1996). Teachers under pressure: Stress in the teaching profession. London: Routledge.

[43] Tschannen-Moran, M., Woolfolk-Hoy, A., \& Hoy, W. K. (1998). Teacher efficacy: Its meaning and measure. Review of Educational Research, 68(2), 202-248.

[44] Tschannen-Moran, A. \& Woolfolk-Hoy, W.K. (2001). Teacher efficacy: Capturing an elusive construct. Teaching and Teacher Education, 17 (7), 783-805.

[45] Wisniewski, L. A., \& Gargiulo, R. M. (1997). Occupational stress and burnout among special educators: A review of the literature. Journal of Special Education, 31 (3), 325-347.

Shahin Vaezi has a Ph.D. in TEFL. She is an assistant professor at the Iran University of Science and Technology. Her research interests are related to teaching English to young learners and metacognition and the processes that one engages in while learning a language. As she works with E-Learning Center at the Iran University of Science and Technology, she has gained insight into teaching English in virtual classrooms. She is also an advocate of trying to reframe ELT research and practice to contextualize it within various cultural contexts. She has published and presented her ideas in various national and international conferences.

Nasser Fallah is an MA candidate of TEFL at Iran University of Science and Technology. His main research interests are reading and vocabulary learning strategies, CALL and educational psychology. He has published a few papers in different international journals. 